\title{
Efficient Stereoselective Carbocyclization to cis-1,4-Disubstituted Heterocycles Enabled by Dual Pd/Electron Transfer Mediator (ETM) Catalysis
}

\author{
Can Zhu, ${ }^{*}{ }^{\#}$ Jie Liu, ${ }^{\#}$ Binh Khanh Mai, Fahmi Himo,* and Jan-E. Bäckvall*
}

Cite This: J. Am. Chem. Soc. 2020, 142, 5751-5759

Read Online

ACCESS | Lill Metrics \& More | 国 Article Recommendations ｜（s Supporting Information

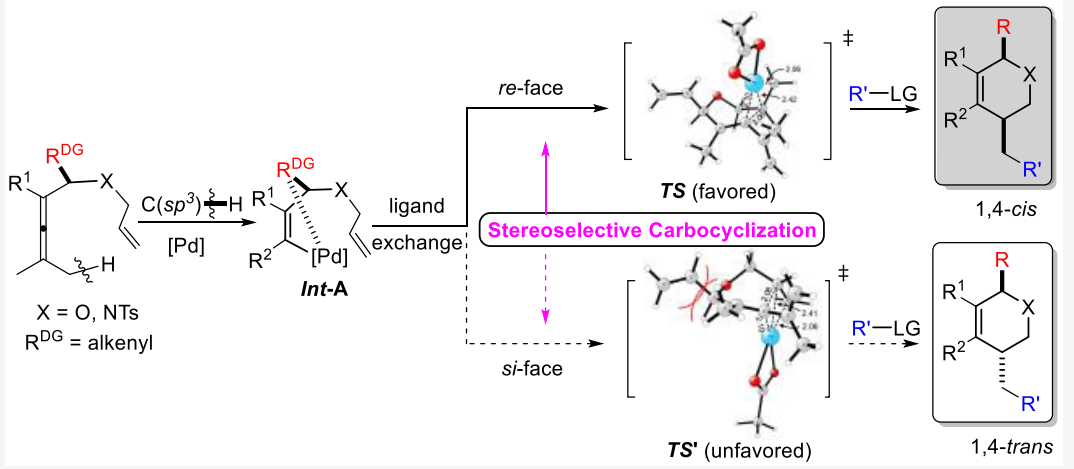

ABSTRACT: An efficient Pd/ETM (ETM = electron transfer mediator)-cocatalyzed stereoselective oxidative carbocyclization of dienallenes under aerobic oxidation conditions has been developed to afford six-membered heterocycles. The use of a bifunctional cobalt complex [Co(salophen)-HQ] as hybrid ETM gave a faster aerobic oxidation than the use of separated ETMs, indicating that intramolecular electron transfer between the hydroquinone unit and the oxidized metal macrocycle occurs. In this way, a class of important cis-1,4-disubstituted six-membered heterocycles, including dihydropyran and tetrahydropyridine derivatives were obtained in high diastereoselectivity with good functional group compatibility. The experimental and computational (DFT) studies reveal that the pendent olefin does not only act as an indispensable element for the initial allene attack involving allenic $\mathrm{C}\left(s p^{3}\right)-\mathrm{H}$ bond cleavage, but it also induces a face-selective reaction of the olefin of the allylic group, leading to a highly diastereoselective formation of the product. Finally, the deuterium kinetic isotope effects measured suggest that the initial allenic $\mathrm{C}\left(s p^{3}\right)-\mathrm{H}$ bond cleavage is the rate-limiting step, which was supported by DFT calculations.

\section{INTRODUCTION}

Six-membered heterocycles are ubiquitous core structures in various natural products, as well as in pharmacologically active substances. ${ }^{1}$ Glucose, the monosaccharide made during photosynthesis from water and carbon dioxide, is one of the most important compounds in the life sciences. ${ }^{2} \alpha$-Dglucopyranose bears the core structure of tetrahydropyran with substituents stereochemically arranged, including 1,2-, 1,3-, and 1,4-cis configurations of two different hydroxyl groups (Scheme 1a). The similar stereochemistry can also be found in many other natural products, such as $(-)$-centrolobine, ophiocerin B, (-)-brevisamide, and pyranicin. ${ }^{3}$ For 1,2- and 1,4-disubstituted six-membered rings, a cis configuration will have one substituent in the equatorial position and the other one in the axial position, where the latter suffers from 1,3diaxial interaction(s) with the axial $\mathrm{C}-\mathrm{H}$ bond(s) (Scheme 1b). ${ }^{4}$ Moreover, the distance between the two substituents in cis-1,4-disubstituted six-membered rings is much greater than that in the corresponding cis-1,2- or 1,3-disubstituted compounds, which is unfavorable for the control of its stereochemistry when the second substituent is introduced. ${ }^{5}$ Therefore, the development of methodologies for efficient synthesis of cis-1,4-disubstituted six-membered rings, including heterocycles, is greatly challenging and highly desirable. ${ }^{6}$

Hetero-Diels-Alder reactions of carbonyl compounds or imines with conjugated dienes constitute a reliable approach toward the synthesis of six-membered heterocycles. ${ }^{7}$ However, for the preparation of cis-1,4-disubstituted products, the reaction requires stereoisomerically pure $(E, E)$ - or $(Z, Z)-1,3$ dienes (Scheme 2a). Moreover, hetero-Diels-Alder reactions

Received: December 19, 2019

Published: February 26, 2020 
Scheme 1. (a) Selected Natural Products Bearing the Core Structure of Six-Membered Heterocycles with 1,2-, 1,3-, or 1,4-cis Configuration. (b) Comparison of the Difficulties on the Selectivity Control for the Synthesis of cis-1,2-, 1,3-, and 1,4-Disubstituted Six-Membered Rings (X, Y = C, O, N. etc.)
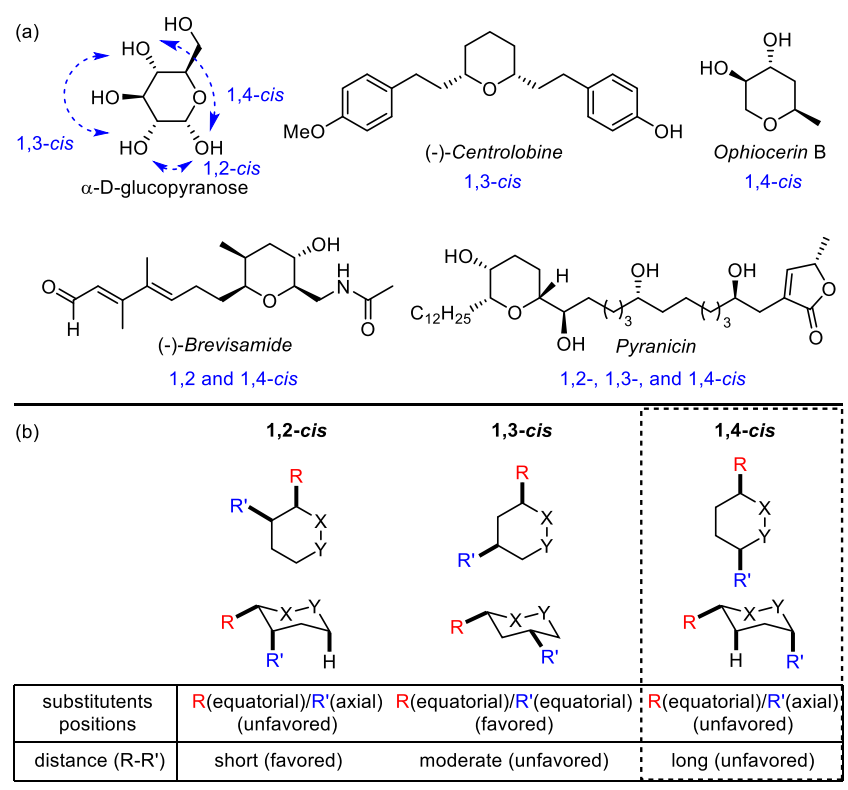

are usually associated with problems in the control of regioselectivity. $^{8}$

Scheme 2. (a) State of the Art and (b) This Work ( $\mathrm{X}=\mathrm{O}$, NR, etc.; DG = Directing Group; $M=$ Metal)

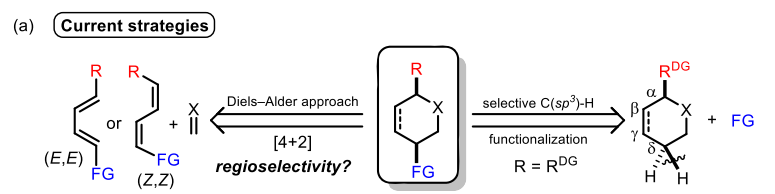

(b) This work: Stereoselective Carbocyclization ('S.C.')

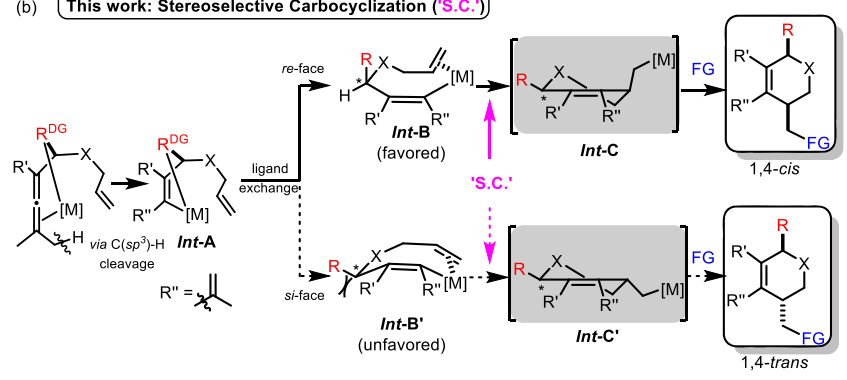

An alternative elegant solution for obtaining cis-1,4disubstituted heterocycles is the utilization of transition metal-catalyzed $\mathrm{C}-\mathrm{H}$ activation reactions (Scheme $2 \mathrm{a}$ ). With a suitable directing group (DG) in the $\mathrm{R}$ group, the transannular $\delta-\mathrm{C}\left(\mathrm{sp}^{3}\right)-\mathrm{H}$ functionalization can be realized with the remote selectivity starting from preformed heterocycles. ${ }^{9,10}$ The newly introduced functional group will then be installed on the same face of the ring as the $\mathrm{R}$ group via a boatconformation intermediate. However, high-temperature conditions are generally required to overcome the energy barrier for $\mathrm{C}\left(\mathrm{sp}^{3}\right)-\mathrm{H}$ activation. ${ }^{9}$ Herein, we disclose an alternative efficient approach for the synthesis of cis-1,4-disubstituted heterocycles via a stereoselective carbocyclization. On the basis of our previous work, ${ }^{11}$ we envisioned that a selective metalation of the $\mathrm{C}-\mathrm{H}$ bond would produce Int-A (Scheme $2 b$ ) with a suitable directing/assisting substituent $\left(\mathrm{R}^{\mathrm{DG}}\right)$. Subsequent intramolecular ligand exchange from the directing group in Int-A to the remote olefin leads to intermediates Int$\mathbf{B}$ and/or Int- $\mathbf{B}^{\prime}$, due to the re- or $s i$-facial coordination of the olefin to the metal. Initial computations indicated that the refacial coordination in conformation Int-B would be favored over the si-facial coordination in Int- $\mathbf{B}^{\prime}$ due to interactions between the $\mathrm{R}$ and $\mathrm{R}^{\prime}$ substituents in Int- $\mathbf{B}^{\prime}$. Surprisingly, the boatlike conformation (Int-B and Int- $\mathbf{B}^{\prime}$ ) was more stable than the corresponding chairlike conformations in both cases. Subsequent migratory insertion in the favored intermediate Int-B would generate Int-C, which further could undergo a coupling reaction to afford the corresponding cis-1,4disubstituted heterocycle as the major product. The corresponding reaction of the less favored intermediate Int- $\mathbf{B}^{\prime}$ would give the trans-1,4-disubstituted heterocycle Int-C'. In this overall transformation, both the ring-closing reaction and the installation of a new functional group (FG) can be efficiently realized in a one-step manner.

\section{RESULTS AND DISCUSSION}

A carbon-carbon double bond is a basic yet crucial functional group in organic chemistry. ${ }^{12}$ It has been found as a useful directing group in organic transformations, for example, in C$\mathrm{H}$ activation reactions. ${ }^{13}$ Moreover, the alkene bond can be diversely transferred to many other functional groups, or easily reduced via hydrogenation. ${ }^{14}$ In a previous study, we found that the pendent olefin unit is an indispensable element for the subsequent allene attack via $\mathrm{C}\left(\mathrm{sp}^{3}\right)-\mathrm{H}$ bond cleavage (Scheme 3a). ${ }^{11}$ Therefore, an olefin unit was introduced on

Scheme 3. (a) Previous Studies and (b) Initial Attempts for this Work

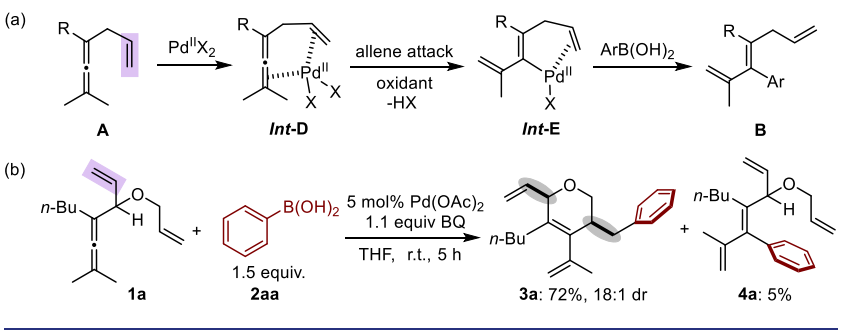

the enallene moiety and evaluated as a directing group in the carbocyclization reaction (Scheme $3 \mathrm{~b}$ ). Our initial attempts began with the coupling reaction of dienallene $\mathbf{1 a}$ with phenylboronic acid (2aa) under the catalysis of palladium with BQ ( $p$-benzoquinone, 1.1 equiv) as the oxidant. Interestingly, the reaction in THF at room temperature (r.t.) for $5 \mathrm{~h}$ afforded the cyclic product $3 a$ in $72 \%$ yield, while the direct phenylation product 4a was obtained only in 5\% yield. Interestingly, the dihydropyran product $3 \mathbf{a}$ was generated in high diastereoselectivity (d.r. = 18:1). From NOE studies of dihydropyran 3a, it was found that the major stereoisomer is the product with cis-1,4-disubstitution.

With these initial results in hand, we turned to optimizing the reaction conditions. In the oxidation reactions, the goal was to use environmentally benign oxidants, such as molecular oxygen. ${ }^{15}$ However, direct reoxidation of $\operatorname{Pd}(0)$ by molecular oxygen is expected to be unfavored due to the high-energy barrier for electron transfer under the reaction conditions of 
the carbocyclization. ${ }^{16}$ Indeed, the attempted palladiumcatalyzed oxidative reaction of 1a using molecular oxygen as the only oxidant without any additives did not give any of the product $3 \mathbf{a}$ or $4 \mathbf{a}$, and the starting material $1 \mathbf{a}$ was recovered in $79 \%$ yield (Table 1 , entry 1 ). A solution to this problem is to

Table 1. Optimization of the Reaction Conditions ${ }^{a}$

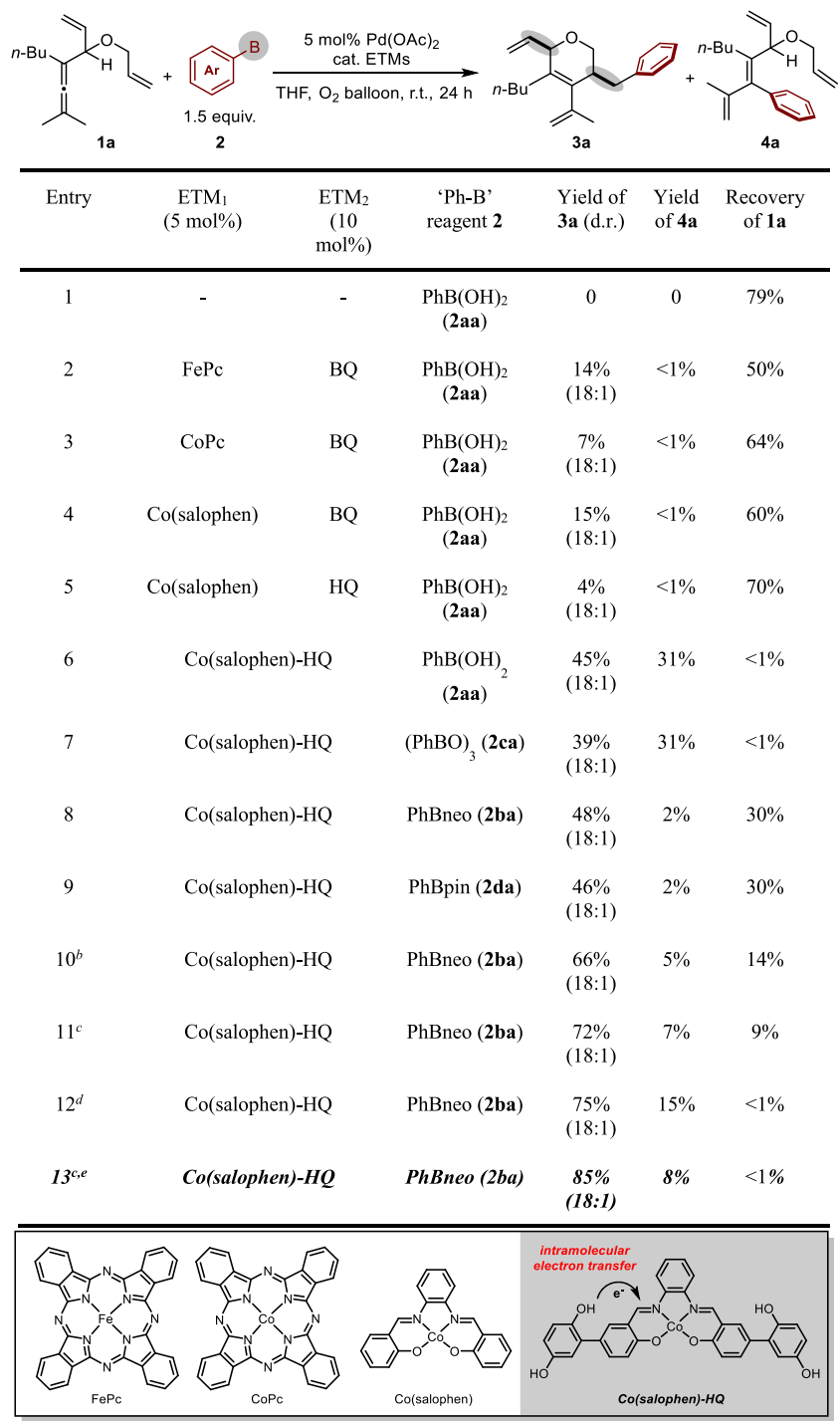

${ }^{a}$ Unless otherwise noted, the following reaction conditions were employed: 1a ( $0.1 \mathrm{mmol}, 1.0$ equiv), $2 \mathrm{a}(0.15 \mathrm{mmol}, 1.5$ equiv $)$, $\mathrm{Pd}(\mathrm{OAc})_{2}(5 \mathrm{~mol} \%), \mathrm{ETM}_{1}(5 \mathrm{~mol} \%), \mathrm{ETM}_{2}(10 \mathrm{~mol} \%)$, in $0.2 \mathrm{M}$ THF, $\mathrm{O}_{2}$ (balloon, $\left.1 \mathrm{~atm}\right)$ at room temperature $\left(23^{\circ} \mathrm{C}\right)$ for $24 \mathrm{~h}$. Yields and conversions were determined by ${ }^{1} \mathrm{HNMR}$ using anisole as internal standard. ${ }^{b} \mathrm{H}_{2} \mathrm{O}$ (0.5 equiv) was added to the reaction mixture. ${ }^{c} \mathrm{H}_{2} \mathrm{O}$ (1.0 equiv) was added to the reaction mixture. ${ }^{d} \mathrm{H}_{2} \mathrm{O}$ (2.0 equiv) was added to the reaction mixture. ${ }^{e}$ The reaction was run with $10 \mathrm{~mol} \%$ of $\mathrm{Co}($ salophen)-HQ for $36 \mathrm{~h}$.

add various established electron transfer mediators (ETMs), including metal macrocyclic complexes and BQ to improve the reoxidation efficiency. ${ }^{16,17}$ To our delight, in the presence of BQ $(10 \mathrm{~mol} \%)$ and catalytic amount of $\mathrm{Fe}(\mathrm{Pc})(\mathrm{Pc}=$ phthalocyanine), a $14 \%$ yield of dihydropyran $3 a$ was obtained with an 18:1 d.r., while 1a was recovered in 50\% yield (Table 1 , entry 2). The employment of $\mathrm{Co}(\mathrm{Pc})$ in place of $\mathrm{Fe}(\mathrm{Pc})$ led to a decrease of the yield of $\mathbf{3 a}$ to $7 \%$ (Table 1, entry 3 ).
Co(salophen) (5 mol \%) together with BQ (10 mol \%) showed slightly higher efficiency in this oxidative carbocyclization with formation of $3 a$ in $15 \%$ yield (d.r. $=18: 1$ ) and recovery of dienallene $1 \mathrm{a}$ in $60 \%$ yield (Table 1 , entry 4 ). Replacing BQ by HQ (hydroquinone) resulted in a lower yield of $3 \mathbf{a}(4 \%)$ (Table 1 , entry 5 ). Interestingly, the use of a hybrid catalyst $\mathrm{Co}$ (salophen)-HQ ${ }^{18}$ in which metal-macrocycle $\mathrm{Co}$ (salophen) $\left(\mathrm{ETM}_{1}\right)$ and two quinone moieties $\left(\mathrm{ETM}_{2}\right)$ are merged into one molecule, significantly improved the yield of the desired product $3 a$ to $45 \%$ (Table 1, entry 6). This improvement is probably due to the higher efficiency of the intramolecular electron transfer in the bifunctional cobalt catalyst [Co(salophen)-HQ], compared to that of the two separate ETMs in entry 5. Unfortunately, in this case, side product 4 a was also formed in $31 \%$ yield, implying a poor chemoselectivity during the reaction. Replacing phenylboronic acid by triphenyl boroxine did not lead to any improvement (entry 7). However, the chemoselectivity toward the formation of 3a was dramatically improved by replacing phenylboronic acid by its neopentylglycol ester (PhBneo) as the arylating reagent (entry 8 vs entry 6). Similarly, PhBpin also showed good reactivity and selectivity albeit in slightly lower yield (46\%, entry 9). Notably, stoichiometric amounts of $\mathrm{H}_{2} \mathrm{O}$ significantly favored the transformation of dienallene $\mathbf{1 a}$ to afford $3 \mathbf{a}$ and $4 \mathbf{a}$ (Table 1 , entries 10-12). ${ }^{19}$ When 2 equiv of $\mathrm{H}_{2} \mathrm{O}$ was added to the reaction mixture, the yield of $3 \mathbf{a}$ was further improved up to $75 \%$, along with the phenylated product $4 \mathrm{a}$ in $15 \%$ yield (Table 1 , entry 12 ). Finally, by increasing the catalyst loading of $\mathrm{Co}$ (salophen)-HQ to $10 \mathrm{~mol}$ $\%$, an optimal yield ( $85 \%$ ) of $3 a$ was obtained in the presence of 1 equiv of $\mathrm{H}_{2} \mathrm{O}$, while side product 4 a was kept as low as $8 \%$ yield (Table 1, entry 13).

Next, the catalytic reaction under aerobic conditions ( $1 \mathrm{~atm}$ of $\mathrm{O}_{2}$ ) at r.t. with different electron transfer mediators (ETMs) was examined using [ $5 \mathrm{~mol} \% \mathrm{Co}$ (salophen $)+10 \mathrm{~mol} \% \mathrm{HQ}$, $[5 \mathrm{~mol} \% \mathrm{Co}$ (salophen) $+10 \mathrm{~mol} \% \mathrm{BQ}]$, or $[5 \mathrm{~mol} \%$ $\mathrm{Co}$ (salophen)-HQ] in the presence of $5 \mathrm{~mol} \% \mathrm{Pd}(\mathrm{OAc})_{2}$ (for details of the reaction conditions, see entries 4-6 in Table 1$)$. As shown in Figure 1, the reaction with hybrid catalyst

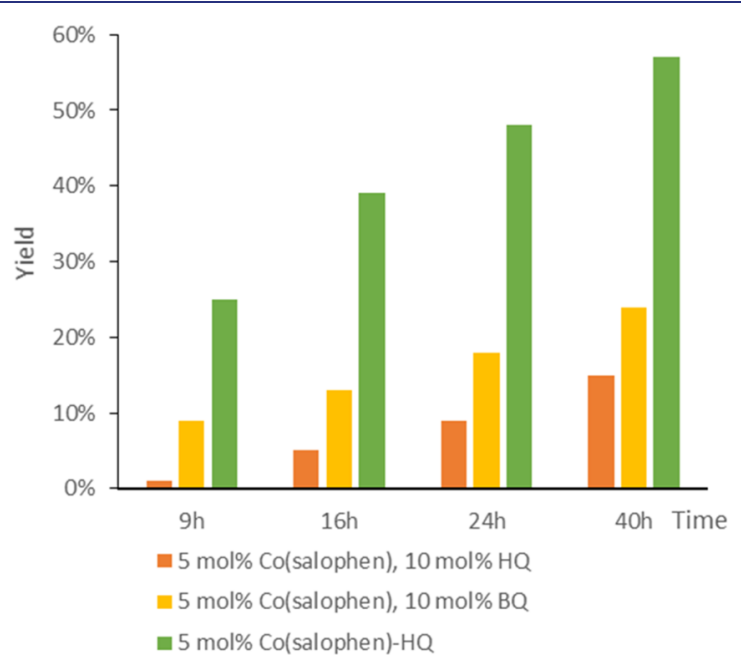

Figure 1. Comparison of catalytic efficiency of different electron transfer mediators (ETMs). Reaction conditions: The reaction was conducted at $25{ }^{\circ} \mathrm{C}$ in THF $(0.5 \mathrm{~mL})$ with 1 a $(0.1 \mathrm{mmol})$, PhBneo $(0.13 \mathrm{mmol})$, and $\mathrm{H}_{2} \mathrm{O}(0.1 \mathrm{mmol})$ in the presence of $\mathrm{Pd}(\mathrm{OAc})_{2}$ (5 mol \%) and $\operatorname{ETM}(\mathrm{s})$ under atmosphere of $\mathrm{O}_{2}$. 
$\mathrm{Co}$ (salophen)-HQ resulted in a much higher reaction rate compared to the reaction with separate use of $\mathrm{Co}$ (salophen) and HQ (or BQ). These results indicate that an intramolecular electron transfer between the hydroquinone unit and the oxidized metal macrocycle occurs in bifunctional hybrid catalyst $\mathrm{Co}$ (salophen)-HQ.

With the optimal reaction conditions in hand, we turned to investigating the substrate scope of this stereoselective carbocyclization reaction (Scheme 4). First, arylboronic acid

\section{Scheme 4. Substrate Scope}

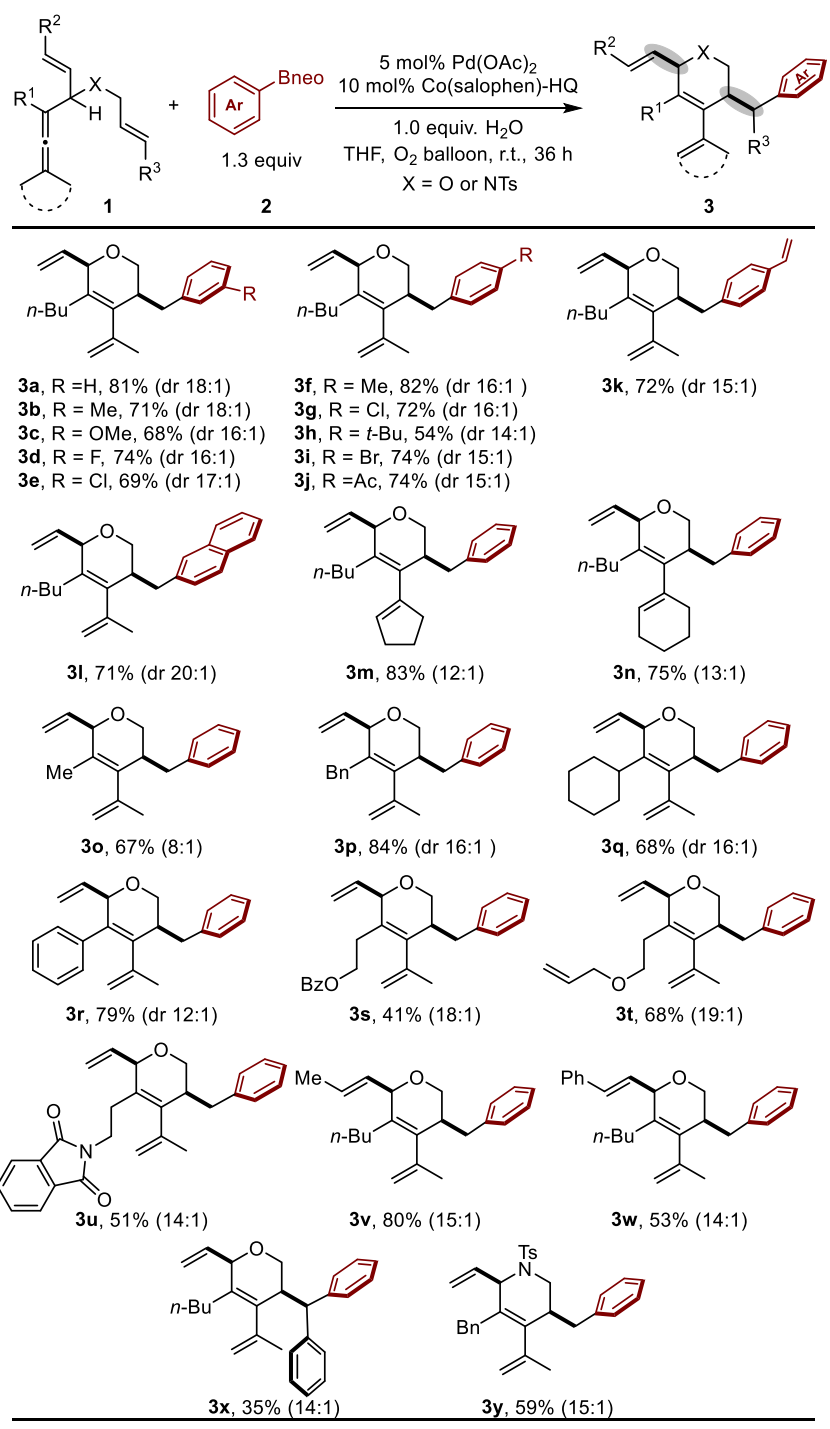

neopentylglycol esters with a range of substituents in the metaposition of the benzene ring were examined: the metaanalogues with electron-donating substituents, such as $\mathrm{Me}$ and $\mathrm{MeO}$, reacted smoothly in high diastereoselectivity (16:1 to 18:1). Substrates bearing electron-withdrawing functional groups in the meta-position, including $\mathrm{F}$ and $\mathrm{Cl}$ worked equally well, affording the corresponding products $3 \mathbf{d}$ and $3 \mathrm{e}$ in 74 and $69 \%$ yields, respectively. Moreover, substituent effects in the para-position were also studied: functional groups, including $\mathrm{Me}, \mathrm{Cl},{ }^{t} \mathrm{Bu}, \mathrm{Br}$, acetyl, and vinyl groups, in the para-position of the benzene ring of arylboronic acid neopentylglycol esters led to the corresponding products $\mathbf{3} \mathbf{f}-\mathbf{3 k}$ in good yields (54$82 \%)$. A higher diastereoselectivity was observed when a 2 - naphthylboronic acid neopentylglycol ester was used, which afforded dihydropyran 31 in a d.r. of 20:1. Furthermore, cycloalkylidene allenes could also be employed, yielding products $3 \mathrm{~m}$ and $3 \mathrm{n}$ in 83 and $75 \%$ yields, respectively. The substituent on the allene moiety $\left(\mathrm{R}^{1}\right)$ can not only be an aliphatic group $\left(\mathrm{R}^{1}=\mathrm{Me}, \mathrm{Bn}\right.$, or $\left.\mathrm{Cy}\right)$, but also be an aromatic group $\left(\mathrm{R}^{1}=\mathrm{Ph}\right)$, and the corresponding dihydropyran derivatives $3 o-3 r$ were obtained in $67-84 \%$ yields accordingly. Functional groups, such as an ester, an ether, and an imide were nicely tolerated under the catalysis of $\mathrm{Pd}$ and $\mathrm{Co}$ (salophen)-HQ yielding products $3 \mathbf{s}-3 \mathbf{u}$ in $41-68 \%$ yields. Not only can a terminal olefin act as the directing/ assisting group, but also an internal olefin was found to promote the reaction as shown by the formation of products $3 \mathrm{v}$ and $3 \mathrm{w}$ in 80 and $53 \%$ yields, respectively. When a phenyl group was introduced on the distal olefin $\left(\mathrm{R}^{3}=\mathrm{Ph}\right)$, the corresponding dihydropyran $3 \mathbf{x}$ was obtained in $35 \%$ yield. Finally, this stereoselective carbocyclization was successfully extended to the synthesis of a tetrahydropyridine derivative $3 y$.

Enzymatic kinetic resolution (EKR) provides an efficient and scalable method for the preparation of chiral secondary alcohols. $^{20}$ EKR of $\alpha$-allenol 5a catalyzed by CALB (Candida antarctica lipase B) afforded $48 \%$ yield of chiral $\alpha$-allenic acetate $(R)-6$ a with $95 \%$ ee on a $1 \mathrm{~g}$ scale (Scheme 5$){ }^{21}$

Scheme 5. Synthesis of Chiral Product $(S)$-5a by Using Enzymatic Kinetic Resolution

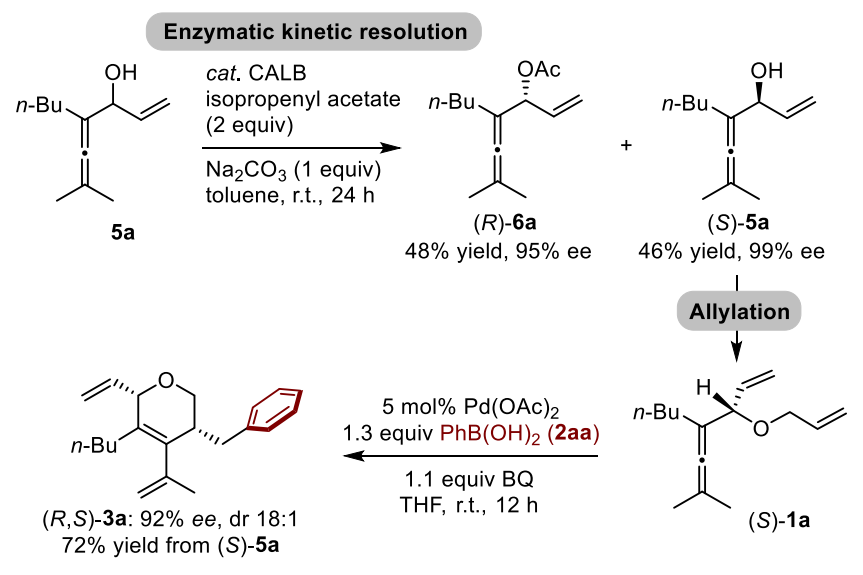

Meanwhile, chiral $\alpha$-allenol (S)-5a was recovered in $46 \%$ yield with $99 \%$ ee. O-allylation of $(S)$-5a and subsequent stereoselective carbocyclization under the catalysis of palladium led to the chiral dihydropyran $(R, S)-3 \mathbf{a}$ in $72 \%$ yield (from $(S)$ 5a), with $92 \%$ ee and 18:1 d.r. using stoichiometric BQ as oxidant.

We believe that the erosion of the ee occurs in the carbocyclization step (second step) of the reaction sequence in Scheme $5 .^{22}$ This was supported by the observation that when the conditions of Scheme 4 were used for the carbocyclization, only $81 \%$ ee of $(R, S)-3$ a was obtained. ${ }^{23}$

Next, to demonstrate the diversity of this stereoselective carbocyclization reaction, enallenyne 7 , bearing the moiety of an internal alkyne, was employed under aerobic oxidative conditions. The corresponding dihydropyran product 8 was isolated in 55\% yield, indicating a selective arylating carbocyclization during the reaction (Scheme 6a). To further confirm the effect of the pendent olefin group in dienallene $\mathbf{1}$, we carried out comparative experiments using enallene $1 \mathbf{a}^{\prime}$, in which the vinyl group in 1a had been replaced by an ethyl 


\section{Scheme 6. Mechanistic Studies}
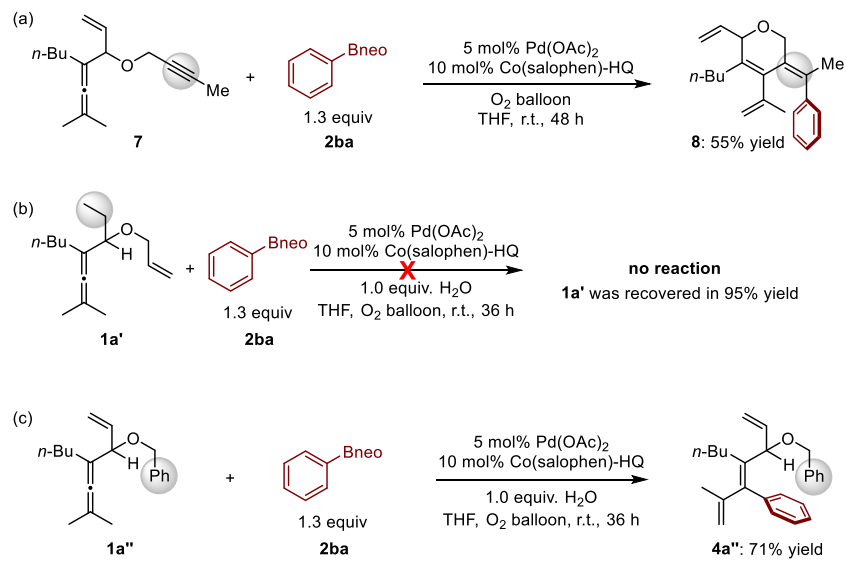

group (Scheme 6b). Attempted reaction of $\mathbf{1} \mathbf{a}^{\prime}$ under standard conditions for $36 \mathrm{~h}$ did not give any product, and neither the pyran derivative $3 a^{\prime}$ nor the triene product $4 a^{\prime}$ could be detected. The starting material $\mathbf{1} \mathbf{a}^{\prime}$ was recovered in $95 \%$ yield. This result indicates that the pendent olefin is an indispensable element for the overall transformations. ${ }^{11}$ Under the standard reaction conditions, direct phenylated product $\mathbf{4 a}^{\prime \prime}$ was obtained in $71 \%$ yield by using enallene $1 \mathbf{a}^{\prime \prime}$, in which the distal vinyl group in 1a had been replaced by a phenyl group (Scheme 6c). This observation again shows the importance of the pendent olefin for the initial activation of the allene via $\mathrm{C}\left(\mathrm{sp}^{3}\right)-\mathrm{H}$ bond cleavage. ${ }^{11}$

To gain a deeper insight into the mechanism of this stereoselective carbocyclization reaction, the deuterium kinetic isotope effects (KIE) were studied. ${ }^{24}$ An intermolecular competition experiment was carried out using a 1:1 mixture of dienallene 1a and $d_{6}-1 \mathrm{a}$ at r.t. for $160 \mathrm{~min}$ in the presence of stoichiometric amounts of BQ (eq 1, Scheme 7). The product

\section{Scheme 7. Kinetic Isotope Effects}

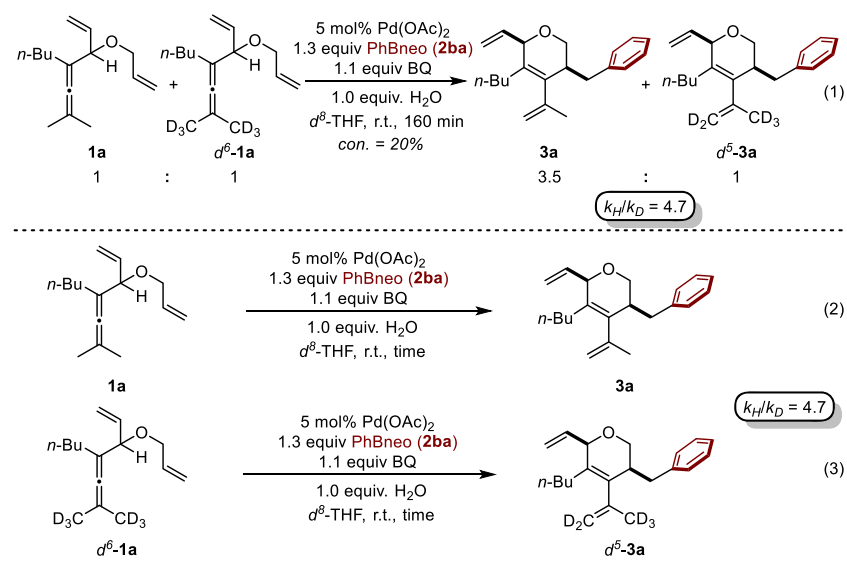

ratio $3 \mathbf{a} / d_{5}-\mathbf{3 a}$ (ca. $20 \%$ conversion) was measured as $3.5: 1$. From the product ratio and the reaction conversion, the competitive KIE for this reaction was determined to be $k_{\mathrm{H}} / k_{\mathrm{D}}$ $=4.7 .25$ Moreover, two parallel experiments with $1 \mathbf{a}$ and $d_{6}-1 \mathbf{a}$ gave the same level of $\operatorname{KIE}\left(k_{\mathrm{H}} / k_{\mathrm{D}}\right.$ from initial rate) value of 4.7 (eqs 2 and 3, Scheme 7). These observed kinetic isotope effects indicate that the allenic $\mathrm{C}-\mathrm{H}$ bond cleavage is the ratelimiting step. The large competitive isotope effect in the allenic $\mathrm{C}-\mathrm{H}$ bond cleavage $\left(k_{\mathrm{H}} / k_{\mathrm{D}}=4.7\right)$ requires that this step is the first irreversible step.
To gain a better insight into the role of the pendent olefin $^{1,26}$ and the origin of the stereoselectivity, we performed density functional theory (DFT) calculations with the dispersion-corrected B3LYP functional (see Supporting Information for computational details) using substrate 1o ( $R$ $=\mathrm{Me})$ as a representative case. On the basis of the DFT calculations (Figure 2), the catalytic cycle for the reaction shown in Scheme 8 is proposed. ${ }^{27}$ The reaction starts with the dissociation of the $\mathrm{Pd}(\mathrm{II})$ acetate trimer to monomer, to which 10 coordinates, giving Int-1. ${ }^{11,28}$ The lowest-energy binding mode is found to be the coordination of the allene moiety and the pendent olefin of 10 (see the Supporting Information for optimized structures). The energy of Int-1 is calculated to be $12.5 \mathrm{kcal} / \mathrm{mol}$ relative to the $\mathrm{Pd}(\mathrm{II})$ acetate trimer (Figure $2 \mathrm{a}$ ). To proceed, the allenic $\mathrm{C}\left(\mathrm{sp}^{3}\right)-\mathrm{H}$ bond cleavage via transition state TS-1 can then take place, generating Int-2. The activation barrier of TS-1 is calculated to be $8.8 \mathrm{kcal} / \mathrm{mol}$ relative to Int1, i.e., $21.3 \mathrm{kcal} / \mathrm{mol}$ relative to the $\mathrm{Pd}(\mathrm{II})$ acetate trimer, which constitutes the rate-determining barrier of the reaction (Figure 2a). ${ }^{29}$ This is consistent with the above KIE experiments for substrate 1a (Scheme 7), showing that this step is the rate-limiting step. ${ }^{30}$ This step is also the first irreversible step of the reaction as can be seen from Figure 2. In addition, the calculated $\mathrm{KIE}$ for the $\mathrm{C}-\mathrm{H}$ cleavage step from DFT calculation is 3.3 , which is consistent with the large competitive isotope effect measured $\left(k_{\mathrm{H}} / k_{\mathrm{D}}=4.7\right)$.

It is interesting to mention that the allenic $\mathrm{C}\left(\mathrm{sp}^{3}\right)-\mathrm{H}$ cleavage transition state $\mathbf{T S}-\mathbf{1}^{\prime}$, in which the distal olefin of $\mathbf{1 0}$ is coordinated to palladium in place of the pendent olefin, was also located (see the Supporting Information for details). The barrier of TS-1' ${ }^{\prime}$ was calculated to be $11.1 \mathrm{kcal} / \mathrm{mol}$ higher in energy than that of TS-1, i.e., $32.4 \mathrm{kcal} / \mathrm{mol}$ relative to $\mathrm{Pd}(\mathrm{II})$ acetate trimer. This result is consistent with the fact that $\mathrm{C}\left(\mathrm{sp}^{3}\right)-\mathrm{H}$ cleavage does not occur if the pendent olefin is removed. ${ }^{11}$

Direct coupling of Int-2 with arylboronic acid neopentylglycol ester gives side product 4 . In the major pathway, the coordination to the palladium ion is changed from the pendent olefin to the distal olefin to form Int-3c, which is calculated to be $9.1 \mathrm{kcal} / \mathrm{mol}$ higher in energy than Int-2. Subsequent carbocyclization via transition state TS-2c (Figure $2 \mathrm{~b})$ is shown to take place, giving six-membered ring intermediate Int-4c, which leads to the formation of product 30 through transmetalation and reductive elimination steps. $^{31,32}$ The activation energy of TS-2c is calculated to be $15.7 \mathrm{kcal} / \mathrm{mol}$ relative to Int-2 (Figure 2a). Finally, the released $\mathrm{Pd}^{0}$ is reoxidized to $\mathrm{Pd}^{\mathrm{II}}$ by the intramolecular ETM system with molecular oxygen as the terminal oxidant, which closes the catalytic cycle (Scheme 8$).{ }^{33}$ These reoxidation steps were not explicitly studied by the current calculations.

Importantly, we also considered the formation of the transisomer of 3o via the carbocyclization transition state TS-2t, which is calculated to be $2.6 \mathrm{kcal} / \mathrm{mol}$ higher in energy than TS-2c. This result is consistent with the experimental finding that the cis-isomer 30 is the main product for this palladiumcatalyzed carbocyclization. By scrutiny of the optimized structures of TS-2c and TS-2t, one source of the energy differences could be identified as being the steric repulsion of the pendent olefin with the methyl moiety (Figure $2 b$ ). This interaction appears in TS-2t, but not in TS-2c, resulting in the higher energy of the former.

It is interesting to mention that other carbocyclization transition states, where the forming ring adopts a more 
(a)

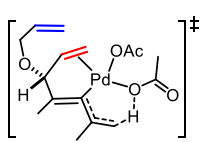

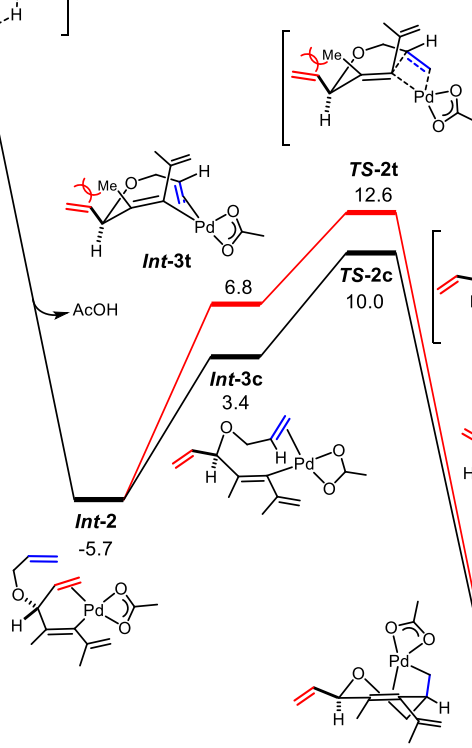

(b)

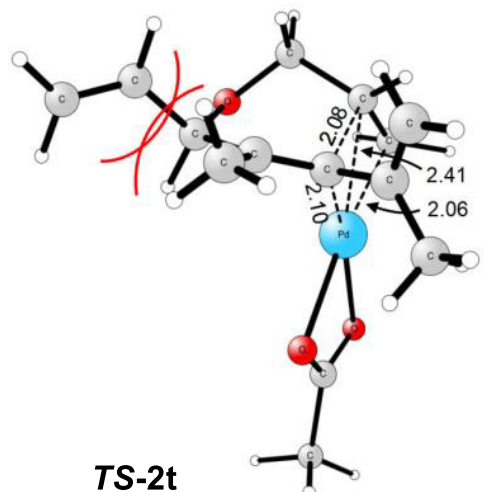

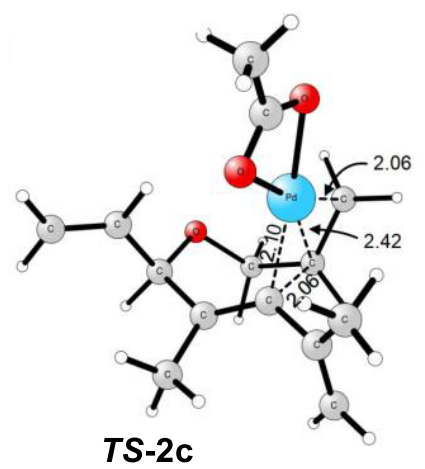

Figure 2. (a) Calculated free energy profile $(\mathrm{kcal} / \mathrm{mol})$ and (b) optimized structures of carbocyclization transition states for the Pd-catalyzed stereoselective carbocyclization. Bond distances are in $\AA$.

\section{Scheme 8. Proposed Mechanism}

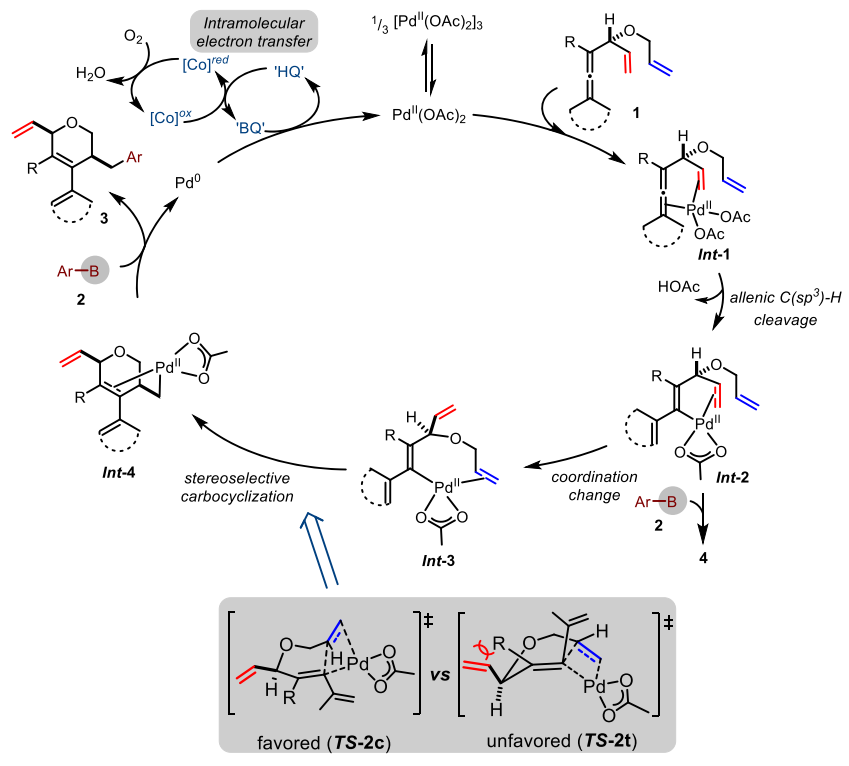

chairlike conformation, were also located (see Supporting Information, Figures S8 and S9). However, these transition states were calculated to be more than $4 \mathrm{kcal} / \mathrm{mol}$ higher in energy than the TS-2c and can therefore be ruled out as feasible conformations for the cyclization.

\section{CONCLUSIONS}

In conclusion, we have developed an efficient Pd/ETMcocatalyzed stereoselective carbocyclization of dienallenes under aerobic oxidation condition that provides access to important cis-1,4-disubstituted six-membered heterocycles. The bifunctional cobalt catalyst [Co(salophen)-HQ] showed high efficiency in this oxidative reaction where molecular oxygen serves as the terminal oxidant. The pendent olefin was shown to be an indispensable element by comparative experiments, and its role is not only to trigger the initial allenic $\mathrm{C}\left(\mathrm{sp}^{3}\right)-\mathrm{H}$ bond cleavage but also to control the stereochemical outcome of the carbocyclization as confirmed by the DFT calculations. Dihydropyran and tetrahydropyridine derivatives with cis-1,4-disubstitution were obtained in high diastereoselectivity. The studies on the kinetic isotope effects, both in competition and in parallel experiments show that the initial allenic $\mathrm{C}\left(\mathrm{sp}^{3}\right)-\mathrm{H}$ bond cleavage is the first irreversible step and also the rate-limiting step as confirmed by the DFT calculations. The second chiral center in the product was successfully induced by the preformed chiral center in the dienallene, which was obtained via enzymatic kinetic resolution. This methodology provides a novel synthesis of cis-1,4-disubstituted six-membered heterocycles, with potential applications in the synthesis of natural products and pharmacologically active substances.

\section{ASSOCIATED CONTENT}

\section{Supporting Information}

The Supporting Information is available free of charge at https://pubs.acs.org/doi/10.1021/jacs.9b13700.

Additional experimental results and procedures and characterization data (NMR, GC, and HPLC spectra, structures), kinetic isotope effect experiments, computational methods, absolute energies, Cartesian coordinates) (PDF) 


\section{AUTHOR INFORMATION}

\section{Corresponding Authors}

Can Zhu - Department of Organic Chemistry, Arrhenius Laboratory, Stockholm University, SE-106 91 Stockholm, Sweden; (1) orcid.org/0000-0001-6604-6173;

Email: zhucaner@gmail.com

Fahmi Himo - Department of Organic Chemistry, Arrhenius Laboratory, Stockholm University, SE-106 91 Stockholm, Sweden; (1) orcid.org/0000-0002-1012-5611;

Email: fahmi.himo@su.se

Jan-E. Bäckvall - Department of Organic Chemistry, Arrhenius Laboratory, Stockholm University, SE-106 91 Stockholm, Sweden; Department of Natural Sciences, Mid Sweden University, SE-851 79 Sundsvall, Sweden; 이이.org/00000001-8462-4176; Email: jeb@organ.su.se

\section{Authors}

Jie Liu - Department of Organic Chemistry, Arrhenius Laboratory, Stockholm University, SE-106 91 Stockholm, Sweden; (1) orcid.org/0000-0002-3105-4840

Binh Khanh Mai - Department of Organic Chemistry, Arrhenius Laboratory, Stockholm University, SE-106 91 Stockholm, Sweden

Complete contact information is available at: https://pubs.acs.org/10.1021/jacs.9b13700

\section{Author Contributions}

${ }^{\#}$ C. Zhu and J. Liu contributed equally to this work.

\section{Notes}

The authors declare no competing financial interest.

\section{ACKNOWLEDGMENTS}

We are grateful for the financial support from the Swedish Research Council (2016-03897), the European Union, the Knut and Alice Wallenberg Foundation (KAW 2016.0072), the Olle Engkvist Foundation, and the Carl Trygger Foundation.

\section{REFERENCES}

(1) (a) Kumar, D.; Sharma, P.; Singh, H.; Nepali, K.; Gupta, G. K.; Jaina, S. K.; Ntie-Kang, F. The Value of Pyrans as Anticancer Scaffolds in Medicinal Chemistry. RSC Adv. 2017, 7, 36977-36999. (b) Miyabe, H.; Miyata, O.; Naito, T. Heterocycles in Natural Product Synthesis, first ed.; Majumdar, K. C., Chattopadhyay, S. K., Eds.; Wiley-VCH Verlag GmbH \& Co. KGaA, 2011.

(2) Kamide, K.; Cellulose and Cellulose Derivatives; Elsevier, 2005, 1652.

(3) Jacques, R.; Pal, R.; Parker, N. A.; Sear, C. E.; Smith, P. W.; Ribaucourt, A.; Hodgson, D. M. Recent Applications in Natural Product Synthesis of Dihydrofuran and -pyran Formation by Ringclosing Alkene Metathesis. Org. Biomol. Chem. 2016, 14, 5875-5893.

(4) Kumazawa, T.; Onda, K.; Okuyama, H.; Matsuba, S.; Sato, S.; Onodera, J.-i. Synthesis of C-glycopyranosylphloroacetophenone Derivatives and Their Anomerization Facilitated by 1,3-Diaxial Interactions. Carbohydr. Res. 2002, 337, 1007-1013.

(5) Chemler, S. R.; Karyakarte, S. D.; Khoder, Z. M. Stereoselective and Regioselective Synthesis of Heterocycles via Copper-Catalyzed Additions of Amine Derivatives and Alcohols to Alkenes. J. Org. Chem. 2017, 82, 11311-11325.

(6) (a) Reddy, B. V. S.; Raju, N. P.; Someswarao, B.; Reddy, B. J. M.; Sridhar, B.; Marumudi, K.; Kunwar, A. C. A Novel Domino Cyclization for the Stereoselective Synthesis of Indeno[2,1-c]pyran and Cyclopenta[c]pyran Derivatives. Org. Biomol. Chem. 2015, 13, 4733-4736. (b) Sequeira, F. C.; Chemler, S. R. Stereoselective
Synthesis of Morpholines via Copper-Promoted Oxyamination of Alkenes. Org. Lett. 2012, 14, 4482-4485. (c) Wertjes, W. C.; Okumura, M.; Sarlah, D. Palladium-Catalyzed Dearomative syn-1,4Diamination. J. Am. Chem. Soc. 2019, 141, 163-167. (d) Okumura, M.; Shved, A. S.; Sarlah, D. Palladium-Catalyzed Dearomative syn-1,4Carboamination. J. Am. Chem. Soc. 2017, 139, 17787-17790. (e) Ge, Y.; Han, Z.; Wang, Z.; Ding, K. Ir-Catalyzed Double Asymmetric Hydrogenation of 3,6-Dialkylidene-2,5-diketopiperazines for Enantioselective Synthesis of Cyclic Dipeptides. J. Am. Chem. Soc. 2019, 141, 8981. (f) Wiesenfeldt, M. P.; Nairoukh, Z.; Li, W.; Glorius, F. Hydrogenation of fluoroarenes: Direct access to all-cis-(multi)fluorinated cycloalkanes. Science 2017, 357, 908-912.

(7) (a) Heravi, M. M.; Ahmadi, T.; Ghavidel, M.; Heidari, B.; Hamidi, H. Recent Applications of the Hetero Diels-Alder Reaction in the Total Synthesis of Natural Products. RSC Adv. 2015, 5, 101999-102075. (b) Tietze, L. F.; Kettschau, G. Hetero Diels-Alder reactions in organic chemistry. In Stereoselective Heterocyclic Synthesis I. Topics in Current Chemistry, vol. 189; Metz, P., Eds.; Springer: Berlin, Heidelberg, 1997.

(8) (a) Brulíková, L.; Harrison, A.; Miller, M. J.; Hlaváć, J. Stereoand Regioselectivity of the Hetero-Diels-Alder Reaction of Nitroso Derivatives with Conjugated Dienes. Beilstein J. Org. Chem. 2016, 12, 1949-1980. (b) Grosso, C.; Liber, M.; Brigas, A. F.; Pinho e Melo, T. M. V. D.; Lemos, A. Regioselectivity in Hetero Diels-Alder Reactions. J. Chem. Educ. 2019, 96, 148-152.

(9) (a) Topczewski, J. J.; Cabrera, P. J.; Saper, N. I.; Sanford, M. S. Palladium-catalysed Transannular $\mathrm{C}-\mathrm{H}$ Functionalization of Alicyclic Amines. Nature 2016, 531, 220-224. (b) Sarkar, S. D. Remote C-H Functionalization by a Palladium-Catalyzed Transannular Approach. Angew. Chem., Int. Ed. 2016, 55, 10558-10560. (c) Cabrera, P. J.; Lee, M.; Sanford, M. S. Second-Generation Palladium Catalyst System for Transannular C-H Functionalization of Azabicycloalkanes. J. Am. Chem. Soc. 2018, 140, 5599-5606. (d) Aguilera, E. Y.; Sanford, M. S. Model Complexes for the Palladium-Catalyzed Transannular $\mathrm{C}-\mathrm{H}$ Functionalization of Alicyclic Amines. Organometallics 2019, 38, 138-142.

(10) For reviews, see: (a) Xu, Y.; Dong, G. $\mathrm{sp}^{3} \mathrm{C}-\mathrm{H}$ Activation via Exo-type Directing Groups. Chem. Sci. 2018, 9, 1424-1432. (b) He, J.; Wasa, M.; Chan, K. S. L.; Shao, Q.; Yu, J.-Q. Palladium-Catalyzed Transformations of Alkyl C-H Bonds. Chem. Rev. 2017, 117, 87548786. (c) White, M. C.; Zhao, J. Aliphatic C-H Oxidations for LateStage Functionalization. J. Am. Chem. Soc. 2018, 140, 13988-14009.

(11) Zhu, C.; Yang, B.; Jiang, T.; Bäckvall, J.-E. Olefin-Directed Palladium-Catalyzed Regio- and Stereoselective Oxidative Arylation of Allenes. Angew. Chem., Int. Ed. 2015, 54, 9066-9069.

(12) Wade, L. G. Organic Chemistry, 6th ed.; Pearson Prentice Hall, 2006; p 279.

(13) For reviews, see: (a) Gandeepan, P.; Cheng, C.-H. TransitionMetal-Catalyzed $\pi$-Bond-Assisted $\mathrm{C}-\mathrm{H}$ Bond Functionalization: An Emerging Trend in Organic Synthesis. Chem. - Asian J. 2015, 10, 824. (b) Minami, Y.; Hiyama, T. Synthetic Transformations through Alkynoxy-Palladium Interactions and $\mathrm{C}-\mathrm{H}$ Activation. Acc. Chem. Res. 2016, 49, 67-77.

(14) (a) Yin, G.; Mu, X.; Liu, G. Palladium(II)-Catalyzed Oxidative Difunctionalization of Alkenes: Bond Forming at a High-Valent Palladium Center. Acc. Chem. Res. 2016, 49, 2413-2423. (b) Margrey, K. A.; Nicewicz, D. A. A General Approach to Catalytic Alkene AntiMarkovnikov Hydrofunctionalization Reactions via Acridinium Photoredox Catalysis. Acc. Chem. Res. 2016, 49, 1997-2006. (c) Zhu, C.; Yang, B.; Qiu, Y.; Bäckvall, J.-E. Olefin-Directed Palladium-Catalyzed Regio- and Stereoselective Hydroboration of Allenes. Chem. - Eur. J. 2016, 22, 2939-2943.

(15) Bäckvall, J.-E. Modern Oxidation Methods, second ed.; WileyVCH: Weinheim, 2011.

(16) Piera, J.; Bäckvall, J.-E. Catalytic Oxidation of Organic Substrates by Molecular Oxygen and Hydrogen Peroxide by Multistep Electron Transfer-A Biomimetic Approach. Angew. Chem., Int. Ed. 2008, 47, 3506-3523. 
(17) (a) Bäckvall, J.-E.; Awasthi, A. K.; Renko, Z. D. Biomimetic Aerobic 1,4-Oxidation of 1,3-Dienes Catalyzed by Cobalt Tetraphenylporphyrin-Hydroquinone-Palladium (II). An Example of Triple Catalysis. J. Am. Chem. Soc. 1987, 109, 4750-4752. (b) Bäckvall, J.-E.; Hopkins, R. B.; Grennberg, H.; Mader, M.; Awasthi, A. K. Multistep Electron Transfer in Palladium-Catalyzed Aerobic Oxidations via a Metal Macrocycle-Quinone System. J. Am. Chem. Soc. 1990, 112, 5160-5166. (c) Gigant, N.; Bäckvall, J.-E. Synthesis of Conjugated Dienes via a Biomimetic Aerobic Oxidative Coupling of Two $\mathrm{C}_{\text {vinyl }}-\mathrm{H}$ Bonds. Chem. - Eur. J. 2013, 19, 10799-10803. (d) Babu, B. P.; Meng, X.; Bäckvall, J.-E. Aerobic Oxidative Coupling of Arenes and Olefins through a Biomimetic Approach. Chem. - Eur. J. 2013, 19, 4140-4135. (e) Volla, C. M. R.; Bäckvall, J.-E. Palladium-Catalyzed Aerobic Domino Oxidative Carbocyclization-Alkynylation of Allenynes. Angew. Chem., Int. Ed. 2013, 52, 14209-14213. (f) Morandi, B.; Wickens, Z. K.; Grubbs, R. H. Practical and General PalladiumCatalyzed Synthesis of Ketones from Internal Olefins. Angew. Chem., Int. Ed. 2013, 52, 2944-2948. (g) Pattillo, C. C.; Strambeanu, I. I.; Calleja, P.; Vermeulen, N. A.; Mizuno, T.; White, M. C. Aerobic Linear Allylic C-H Amination: Overcoming Benzoquinone Inhibition. J. Am. Chem. Soc. 2016, 138, 1265-1272. (h) Naidu, V. R.; Posevins, D.; Volla, C. M. R.; Bäckvall, J.-E. Selective Cascade Reaction of Bisallenes via Palladium-Catalyzed Aerobic Oxidative Carbocyclization-Borylation and Aldehyde Trapping. Angew. Chem., Int. Ed. 2017, 56, 1590-1594.

(18) (a) Purse, B. W.; Tran, L.-H.; Piera, J.; Åkermark, B.; Bäckvall, J.-E. Synthesis of New Hybrid Hydroquinone/Cobalt Schiff Base Catalysts: Efficient Electron-Transfer Mediators in Aerobic Oxidation. Chem. - Eur. J. 2008, 14, 7500-7503. (b) Johnston, E. V.; Karlsson, E. A.; Lindberg, S. A.; Åkermark, B.; Bäckvall, J.-E. Efficient Reoxidation of Palladium by a Hybrid Catalyst in Aerobic Palladium-Catalyzed Carbocyclization of Enallenes. Chem. - Eur. J. 2009, 15, 6799-6801. (c) Johnston, E. V.; Karlsson, E. A.; Tran, L.-H.; Åkermark, B.; Bäckvall, J.-E. Efficient Synthesis of Hybrid (Hydroquinone-Schiff base)cobalt Oxidation Catalysts. Eur. J. Org. Chem. 2009, 2009, 3973-3976. (d) Liu, J.; Ricke, A.; Yang, B.; Bäckvall, J.-E. Efficient Palladium-Catalyzed Aerobic Arylative Carbocyclization of Enallenynes. Angew. Chem., Int. Ed. 2018, 57, 16842-16846. (e) For a hybrid catalyst consisting of a porphyrin and quinones, see: Grennberg, H.; Faizon, S.; Bäckvall, J.-E. Cobalt Tetra(hydroquinone)porphyrin: An Efficient Electron Transfer Reagent in Aerobic Pd-Catalyzed 1,4-Diacetoxylation of 1,3-Cyclohexadiene. Angew. Chem., Int. Ed. Engl. 1993, 32, 263-264.

(19) There is an equilibrium between $\mathrm{PhB}(\mathrm{OH})_{2}$ and the corresponding neopentyl glycol boronic ester (eq 4).)

$\mathrm{PhB}(\mathrm{OH})_{2}+\mathrm{HO} \mathrm{OH} \rightleftharpoons \mathrm{Ph}_{\mathrm{O}}^{\prime} \mathrm{O}_{\mathrm{O}}^{\mathrm{O}} \mathrm{X}+2 \mathrm{H}_{2} \mathrm{O}$

Addition of water can promote hydrolysis of this ester toward the formation of $\mathrm{PhB}(\mathrm{OH})_{2}$, therefore increasing the reaction rate and yield of the product. For a similar effect by water see: Bartholomeyzik, T.; Pendrill, R.; Lihammar, R.; Jiang, T.; Widmalm, G.; Bäckvall, J.-E. Kinetics and Mechanism of the Palladium-Catalyzed Oxidative Arylating Carbocyclization of Allenynes. J. Am. Chem. Soc. 2018, 140, 298-309.

(20) (a) Verho, O.; Bäckvall, J. E. Chemoenzymatic Dynamic Kinetic Resolution: A Powerful Tool for the Preparation of Enantiomerically Pure Alcohols and Amines. J. Am. Chem. Soc. 2015, 137, 3996-4009. (b) Yang, B.; Zhu, C.; Qiu, Y.; Bäckvall, J. E. Enzyme- and Ruthenium-Catalyzed Enantioselective Transformation of $\alpha$-Allenic Alcohols into 2,3-Dihydrofurans. Angew. Chem., Int. Ed. 2016, 55, 5568-5572.

(21) Zhu, C.; Schwarz, J. L.; Cembellín, S.; Greßies, S.; Glorius, F. Highly Selective Manganese(I)/Lewis Acid Cocatalyzed Direct C-H Propargylation Using Bromoallenes. Angew. Chem., Int. Ed. 2018, 57, 437-441.

(22) It is likely that some $\mathrm{C}-\mathrm{H}$ bond cleavage by $\mathrm{Pd}(\mathrm{II}$ ) occurs at the chiral center during carbocyclization. Since we were not able to determine the ee value of the product $(S)-\mathbf{1 a}$ by chiral GC or HPLC, we cannot rule out that some erosion of ee also occurs in the first step. (23) In the reaction of enantioenriched substrate $(S)-1$ a (99\% ee) to give $(R, S)$-3a, a greater ee erosion occurs when using the $\mathrm{Co} / \mathrm{Pd}$ system of Scheme 4 . In this case only $81 \%$ ee of the product $(R, S)-3$ a was obtained from enantioenriched substrate $(S)$-5a, with similar yield (71\% yield) and diastereoselectivity (d.r. 18:1).

(24) Simmons, E. M.; Hartwig, J. F. On the Interpretation of Deuterium Kinetic Isotope Effects in $\mathrm{C}-\mathrm{H}$ Bond Functionalizations by Transition-Metal Complexes. Angew. Chem., Int. Ed. 2012, 51, 3066-3072.

(25) Chen, C.-S.; Fujimoto, Y.; Girdaukas, G.; Sih, C. J. Quantitative analyses of biochemical kinetic resolutions of enantiomers. J. Am. Chem. Soc. 1982, 104, 7294-7299.

(26) For DFT calculations on the role of a pendent olefin for allenic $\mathrm{C}\left(\mathrm{sp}^{3}\right)-\mathrm{H}$ activation in related systems, see: (a) Zheng, X.-W.; Nie, L.; Li, Y.-P.; Liu, S.-J.; Zhao, F.-Y.; Zhang, X.-Y.; Wang, X.-D.; Liu, T. Mechanistic Insight into the Selective Olefin-directed Oxidative Carbocyclization and Borylation by A Palladium Catalyst: A Theoretical Study. RSC Adv. 2017, 7, 5013-5018. (b) Han, L.; Liu, T. A Theoretical Study on the Palladium-catalyzed Oxidative Carbocyclization-alkoxycarbonylation of bisallenes to construct seven-membered carbocycles Assisted by Olefins. Org. Biomol. Chem. 2017, 15, 5055-5061.

(27) (a) Franzén, J.; Bäckvall, J.-E. Carbon-Carbon Bond Formation in Palladium(II)-Catalyzed Allylic Oxidation: A Novel Oxidative Carbocyclization of Allene-Substituted Olefins. J. Am. Chem. Soc. 2003, 125, 6056-6057. (b) Persson, A. K. Å.; Jiang, T.; Johnson, M.; Bäckvall, J.-E. Palladium-Catalyzed Oxidative Borylative Carbocyclization of Enallenes. Angew. Chem., Int. Ed. 2011, 50, 6155-6159. (c) Jiang, T.; Bartholomeyzik, T.; Mazuela, J.; Willersinn, J.; Bäckvall, J.-E. Palladium(II)/Brønsted Acid-Catalyzed Enantioselective Oxidative Carbocyclization-Borylation of Enallenes. Angew. Chem., Int. Ed. 2015, 54, 6024-6027. (d) Zhu, C.; Yang, B.; Bäckvall, J.-E. Highly Selective Cascade $\mathrm{C}-\mathrm{C}$ Bond Formation via Palladium-Catalyzed Oxidative Carbonylation-Carbocyclization-Carbonylation-Alkynylation of Enallenes. J. Am. Chem. Soc. 2015, 137 (37), 11868-11871. (e) Yang, B.; Qiu, Y.; Bäckvall, J.-E. Control of Selectivity in Palladium(II)-Catalyzed Oxidative Transformations of Allenes. Acc. Chem. Res. 2018, 51, 1520-1531. (f) Zhu, C.; Yang, B.; Qiu, Y.; Bäckvall, J.-E. Highly Selective Construction of Seven-Membered Carbocycles by Olefin-Assisted Palladium-Catalyzed Oxidative Carbocyclization-Alkoxycarbonylation of Bisallenes. Angew. Chem., Int. Ed. 2016, 55, 14405-14408.

(28) (a) Zhu, C.; Yang, B.; Mai, B. K.; Palazzotto, S.; Qiu, Y.; Gudmundsson, A.; Ricke, A.; Himo, F.; Bäckvall, J.-E. Highly Selective Palladium-Catalyzed Hydroborylative Carbocyclization of Bisallenes to Seven-Membered Rings. J. Am. Chem. Soc. 2018, 140, 1432414333. (b) Zhu, C.; Yang, B.; Qiu, Y.; Bäckvall, J.-E. Olefin-Directed Palladium-Catalyzed Regio- and Stereoselective Hydroboration of Allenes. Chem. - Eur. J. 2016, 22, 2939-2943.

(29) We also calculated the eight-membered TS for the allenic $\mathrm{C}-\mathrm{H}$ bond cleavage, in which the other acetate oxygen is involved. This TS is calculated to be $2.5 \mathrm{kcal} / \mathrm{mol}$ higher in energy than TS-1. An agostic interaction, which occurs in TS-1 but not in the eightmembered TS, is one of the factors that stabilizes TS-1. For details, see the Supporting Information, Figure S7.

(30) (a) Qiu, Y.; Mendoza, A.; Posevins, D.; Himo, F.; Kalek, M.; Bäckvall, J. E. Mechanistic Insight into Enantioselective PalladiumCatalyzed Oxidative Carbocyclization-Borylation of Enallenes. Chem. Eur. J. 2018, 24, 2433-2439. (b) Zhang, J.; Shan, C.; Lv, K.; Zhu, L.; Li, Y.; Liu, T.; Lan, Y. Mechanistic Insight into Palladium-Catalyzed Carbocyclization-Functionalization of Bisallene: A Computational Study. ChemCatChem 2019, 11, 1228-1237.

(31) In principle transmetalation could occur before carbocyclization. However, the activation barrier for transmetalation from Int-2 is calculated to be $21.0 \mathrm{kcal} / \mathrm{mol}$ relative to Int -2 , which is $5.3 \mathrm{kcal} / \mathrm{mol}$ higher in energy than TS-2c. Moreover, transmetalation from Int-3 has an even higher barrier, $10.5 \mathrm{kcal} / \mathrm{mol}$ higher than the 
transmetalation from Int-2. Thus, the DFT results support that the carbocylization step occurs before transmetalation.

(32) The $\beta$-H elimination products were not observed in the experiments. The DFT calculations show that alkene complexation in Int-4c is stabilized by the olefin coordination to Pd. The trans relationship between $\mathrm{Pd}$ and $\mathrm{H}$ would disfavor the $\beta$ - $\mathrm{H}$ elimination process. As a result, a fast trapping of Int $-4 \mathrm{c}$ by PhBneo occurs and generates the corresponding cyclization product.

(33) Anson, C. W.; Ghosh, S.; Hammes-Schiffer, S.; Stahl, S. S. $\mathrm{Co}$ (salophen)-Catalyzed Aerobic Oxidation of $p$-Hydroquinone: Mechanism and Implications for Aerobic Oxidation Catalysis. J. Am. Chem. Soc. 2016, 138, 4186-4193. 